\title{
CORRESPONDENCE
}

\section{REQUEST FOR REPRINTS OF ARTICLES ON STRESS AND THE ADAPTIVE HORMONES}

\section{To the Editorial Committee of the British Journal of OphthalmologY}

DeAR SIRS-In perusing the current literature with which your Journal is concerned, we note that an ever-increasing number of articles deal with problems pertaining to research on "stress" and the so-called "adaptive hormones" (ACTH, STH, corticoids, adrenergic substances, etc.).

We are writing you because, in our opinion, the success of research in this complex and rapidly developing field largely depends upon the prompt availability and evaluation of relevant publications, a task for which we should like to solicit your readers' assistance.

In 1950, our Institute initiated the publication of a series of reference volumes entitled "Annual Reports on Stress" (Acta Medical Publishers, Montreal) in which the entire current world literature is surveyed every year (usually between 2,000 and 4,000 publications). Up to now, we have had to compile the pertinent literature partly from medical periodicals, monographs, and abstract journals, and partly from reprints sent to us by the authors themselves. Of all these, reprints have proved to be the best source of data which we felt deserved prompt attention in our annual reports. Hence, in the past, we have sent out several thousand individual reprint requests to authors whom we knew to be currently engaged in research on stress and allied topics. Even this procedure did not give us the wide coverage which would be desirable, because it is materially impossible to contact all these authors individually and it often takes too much time to get the requested reprints.

It is evident that in order to insure prompt inclusion of publications in the annual reports, these surveys must develop into a cooperative effort between the authors of original papers and the reviewers. This cooperation has been greatly enhanced of late by the publication of announcements, in several medical journals, encouraging investigators interested in stress research to send us their reprints as soon as they become available.

We should be grateful if by the publication of this note, you would bring this problem to the attention of your readers.

We are, Gentlemen,

Very sincerely yours,

Hans Selye,

Alexander Horava.

Institute of EXPerimental Medicine and Surgery, University of Montreal, Canada.

January 21, 1953.

\section{BOOK REVIEW}

Retrolental Fibroplasia and Other Forms of Pseudo-Glioma. By C. H. O. M. von WinNING. 1952. Pp. 116, 32 tables, 63 figs., 314 refs. The Hague.

This is an excellent review of the literature on retrolental fibroplasia together with a report of the first 37 cases of this condition-which have occurred in the Netherlands 